Billett S (2001) Vocational educators: Understanding practice at work. In C. Velde (ed.) International Perspectives on Competence in the Workplace: Research Policy and Practice (pp41-64). Kluwer Academic Publishers, Dordecht, The Netherlands.

\title{
CHAPTER 5: VOCATIONAL EDUCATORS: UNDERSTANDING PRACTICE AT WORK
}

\author{
STEPHEN BILLETT \\ Faculty of Education \\ Griffith University
}

\section{Introduction}

This chapter uses sociohistorical and sociocultural theory to propose a means to understand and identify what comprises competence in vocational educators' practice. In doing so it does not aim to be prescriptive. Only when the perspectives that contribute to a view of what comprises the occupational practice in the particular cultural setting (e.g. nation, state, educational system) and the situational requirements arising from the particular manifestation of practice have been accounted for can the requirements for competent performance be understood fully. Accordingly, this chapter aims to describe a means by which these requirements can be identified and described. The conceptual basis is founded within what has been described as cultural-historical activity theory (Cole 1998) or what Wertsch (1991) refers to as the sociocultural approach. An analysis based on two lines of social development are deployed in this account; one informing the occupational view and one the situational requirements. The culturally determined need for vocational educators is found in sociohistorical and sociocultural sources. Together, these sources provide the goals for, procedures and conceptions of vocational educators' practice and inform how they have evolved into a particular sociocultural practice or occupation (Scribner 1985). The delineation of the occupation permits an understanding of how vocational educators' practice is distinct from those in other educational sectors (e.g. compulsory or higher education). Moreover, it explains also how the occupational practice, and therefore what is required for performance, differs across countries according to their cultural needs. The occupational conception is typically that which is used as a basis for identifying the content and intents of courses that prepare or develop further vocational educators, or as a basis for understanding their work for employment and promotional purposes within a cultural setting (e.g. nation, state). However, this conception is unlikely to be singular or uniformly agreed up. Instead, within the cultural setting, different interests may well have distinct views about what comprises the occupation role and should constitute its primary focus. So the conception of the occupation is likely to be contested. However, while deeply informative and purposeful in its own right, this historically and culturally constructed conception of vocational educators' work is an ideal that is disembedded from actual practice, yet is prescriptive. Only when occupational practice is manifested (embedded) in particular circumstances is it possible to identify the actual requirement for performance at work. This is because situational requirements shape the basis by which work has to be conducted and judgements made about performance (Billett 1998). What may be deemed competent performance in one setting may be quite inappropriate in another. Accordingly, it is not possible to advance a view about what comprises vocational educators' practice and performance without accounting for these situational requirements.

Together, and drawing on these two lines of development, a scheme is advanced for identifying and describing what comprises competence in vocational educators' work. The scheme comprises, firstly, a sociocultural and historical account for a idealized but contested conception of vocational educators' practice and, secondly, situational factors comprising categories of activities and interdependence that account for how vocational educators' work is manifested in particular circumstances. Prescribing at the occupational level (what should be) and describing at the situational level (what is), respectively yields a basis for understanding vocational educators' practice. There is both reciprocity and tensions between these two levels; between the contested, idealized but disembedded occupational account and the embedded and actual situational account. These tensions are likely to endure. Regardless, they need to be acknowledged when considering the requirements for performance of vocational educators, how they should be prepared for their role and how their professional development might best proceed. 
The chapter commences by positioning its project within the sociocultural approach. This is followed by an account of understanding vocational teachers' practice at the occupational or sociocultural level that takes into account the distinctiveness of the occupational practice as well as its variations and evolving form. Following this, a means to describe the situational requirements for practice is advanced. Finally, the reciprocity and tensions between these two levels of social practice are used as a basis for reconciling these levels as a means to propose how competence will be identified.

\section{The sociocultural approach}

The theoretical orientation adopted in this chapter is found within what has been described as culturalhistorical activity theory (Cole 1998) or the sociocultural approach to activity and mind Wertsch (1991). The genesis of this orientation is found in the work of Vygotsky $(1978,1987)$, his colleagues Leonteiv (1981) and Luria (1976) and recent adherents (e.g. Scribner 1985, Cole 1985, 1998, Wertsch 1991, 1998). It is premised on the view that the knowledge required for purposeful goal-directed activity, such as performance at work, is sociohistorically and socioculturally sourced, mediated as well as socially situated (see Figure 1). Beyond involuntary behaviours, individuals' mental functions are proposed as being socially shaped (Vygotsky 1978, Wertsch 1991), as are the activities in which individuals engage and from which they construct knowledge (Cole 1998, Scribner 1985, Rogoff 1990). That is, how people know and learn is socially influenced and the origins of knowledge they learn are found in sociohistorical, sociocultural and situational sources. In particular, higher orders of knowledge are held to be socially sourced, rather than a product of individual biological determination (Vygotsky 1978). The social basis of the knowledge required for performance, and the thinking and acting associated with it are so richly interwoven as to be inseparable (Scribner \& Beach 1993, Wenger 1998). As Wertsch proposes:

The basic tenet of the sociocultural approach to mind is that human mental functioning is inherently situated in social interactional, cultural, institutional and historical context. Such a tenet contrasts with approaches that assume implicitly or explicitly, that it is possible to examine mental processes such as thinking or memory independently of the sociocultural setting in which individuals and groups function. (Wertsch 1991: 85)

The social basis for knowing is central to understanding vocational educators' practice as it informs how this practice itself is shaped by cultural need and social factors. It also informs the means by which individuals are likely to learn the knowledge required for their practice. Because cultural need develops and transforms over time, the sociocultural approach is necessarily conceived of within and is inclusive of four embedded levels or lines of development. These are: (i) phylogenesis - the history of our species; (ii) sociocultural - cultural-history - the history of a cultural group; and (iii) ontogeny - individuals' life history - moment-to-moment interactions that are the basis of our experience (Cole 1998). There is also, fourthly, the community of practice (Lave \& Wenger 1991) or situational level in which the moment-to-moment interactions which comprises our ontogeny occur and are shaped by situational factors (Billett 1998). These lines of social development are sources of distinct contributions to practice yet apart from the situational level are disembedded from actual practice. However, each makes useful contributions to understanding competence at work.

The historic (phylogenetic) level reflects the evolving and accumulated contributions of the history of our species. This level informs about requirements for vocational educators that are likely to be common to teachers in other sectors of education, and be of a general kind. These requirements are a product of evolving understanding about teachers' work. They are premised on the need for teachers and might include teachers having to be knowledgeable in their content, being fair, consistent and ethical in their practice etc. At this level, procedures common to teaching might be advanced such as determining students' prior knowledge and using that as a basis for formulating curriculum. These goals and procedures have evolved over time and are based on earlier precedents. If there were interest in developing a course for teachers across all sectors of education, an appraisal of need could be located at the phylogenetic level. Also, in the evolving history of our species, the need for vocational educators has been identified. However, while this level is embedded in evolving sociohistoric practices it is remote from the specific cultural needs for different kinds of teachers, which are identifiable at the sociocultural level.

The sociocultural level of development (Scribner 1985) provides a basis for the expression of particular cultural needs found in cultural settings such as nation states. Therefore, as an expression of particular 
needs, this level can be used for identifying the requirements of vocational educators as an occupational practice responding to a particular set of cultural needs that are in some ways distinct. Scribner (1985) referred to practices of counting that were shaped by particular cultural needs i.e. the requirements for counting and the procedures adopted for particular purposes for counting in different cultures. So although informed by mathematical concepts and procedures that evolved over time (phylogentically), these concepts and procedures were transformed by particular sociocultural needs. The kinds of counting undertaken and the procedures adopted for that counting were a product of the needs of a particular cultural setting. Vocational educators' practice will have concepts and procedures common to those in compulsory and higher education (e.g. the need for abilities in teaching, depth and currency of content, professional conduct in working with students and assessing their work with validity and reliability). However, these procedures and concepts are likely to manifest themselves in particular ways given the exigencies of the settings in which they are enacted. Within some cultural settings there is a need for teachers who can develop the vocational knowledge of others. Arising from this need are requirements for vocational educators to be vocationally knowledgeable, to be able to practice competently the skills they teach, have the capacity to teach adults, view students as peers etc. etc. These needs can be seen as being distinct from the requirements for other educational sectors. This is in part as a product of the particular content they are expected to teach and the cohorts of students that they will likely teach. However, this need is more clearly identified in some cultural settings than others. Not all countries have vocational education systems and in those that do it is manifested in different ways. As with the socio-historic level of development, although the sociocultural conception of the vocational educator is embedded in a particular set of cultural needs, it is still abstracted from practice. The sociocultural or occupational domain can best be thought of as an abstracted, contested and 'idealized' view of cultural practice. It cannot be observed, only conceptualised as intentions for practice. Often it is constructed from an amalgam or aggregation of ideas and instances of actual practice. Only when these contributions are applied in and shaped by particular circumstances can vocational educators' practice at work be actually observed and the requirements for practice identified. Those readers familiar with the processes of developing vocational curriculum may well recognize the process that occurs when developing national core curriculum. An analogous situation, also familiar to many in vocational education, is that between the 'industry' and enterprise view of what is required for performance at work. The 'industry' perspective is often one that is an aggregation of enterprise needs. Yet, nobody actually works in an 'industry'. Individuals work in enterprises or for themselves. Hence, although the industry view may seek to reflect what happens in enterprises it is still remote from actual work practice. Therefore, the situational requirements of practice need to be considered.

Each work practice is likely to be rendered unique by the range of situational requirements that are a product of its activity system (Leonteiv 1981, Engestrom 1993). Even the most apparently uniform work practice (e.g. fast food outlet) will have situational requirements (interactions and activities) that render it distinct in some ways. Consequently, what passes as expertise in one setting may be viewed as being inappropriate in another (Billett 1995). To use an example from compulsory education, the teacher who is competent in a small country school could not be assumed to be competent in a tough inner city school or one that has a high academic profile. Similarly, the vocational educator who is valued for teaching a broad range of courses in one college setting may be seen to lack specialization or particular expertise in another. So although vocational teaching is commonly practiced, a range of situational factors, (e.g. location, access to resources, cohort of students, cohort of staff, courses taught, administrative structures and values, those of the community it serves) will contribute to what comprises competence in a particular educational setting. Consequently, what is required for performance needs to be understood at the situational or communities of practice level where the occupational practice is actually enacted (Lave \& Wenger 1991, Wenger 1998). From what has been advanced, conceptualisations of the requirements for performance need to be informed by: (a) the abstracted and disembedded occupational view (sociocultural practice) and (b) the requirements of the particular setting in which practice is enacted. In referring to conceptions of social practice that are analogous to those advanced here, Wenger (1998) claimed that the local and the global are not different historical moments in an expanding world. Instead, they are "related levels of participation that always coexist and shape each other” (p.131). This view is consistent with the account of understanding practice proposed here.

Figure 1 draws upon earlier work to model the genesis of knowledge and activities (Billett 1998). It depicts the sociohistorical, sociocultural and situational levels of and bases for understanding vocational educators' practice as outlined above. The sociocultural and sociohistorical levels for understanding the requirements of vocational educators' occupational practice are presented in the first two boxes and discussed in Section 3. Following on, in Section 4, the work practice level is depicted and detailed further. These levels of social practice evolving independently of each other and yet are interdependent; they co-exist and shape each 
other. Changes in practice have the potential to be sourced at any of these levels of practice with the effect of the transformation being shaped by the breadth of the applicability of the transformation. The change could be one that has broad application across educational sectors; for example the impact of constructivist theories of learning referred to above might reverberate through all levels. Conversely, the change might be only applicable to vocational education, for example the belated realization of the complexity and demanding character of vocational work. Alternatively, transformations might relate to the requirements to assist a particular cohort of learners (e.g. school-leavers, non-English speaking, those with previous low achievement in education) understand a specific vocational practice that is particularly difficult to learn (e.g. principles of hygiene required in airline food preparation, how data processing occurs).

Sociohistorical level (phylogenetic)

Historical derived and evolving knowledge Wertsch 1985 Scribner 1985

(e.g. teaching and instruction ) Guiding concepts and procedures (bases for interactions with students, pedagogic and content knowledge, assessment principles)

Sociocultural level
Historically derived knowledge transformed by cultural needs (Scribner 1985) (Occupational level)
(e.g. vocational educaton educator, primary, preschool teachers, university lecturer)
norms, practice and expectations (particular approaches and methods of teaching and assessment, educational tasks, approaches to work
with particular cohorts of staff)
Activities and Interdependence (Billett 1999) expected of the occupation

Work practice level - Community of practice
Particular sociocultural practice shaped by a complex of circumstantial social factors
(Lave \& Wenger 1991, Wenger 1998) (activity system Engestrom 1993; Leont'ev 1981)
norms and values which embody the community -
(e.g. particular vocational education setting - metropolitan vocational college or remote vocational education centre, vocational education
unit in a prison, or in a high school)
Situational factors of Activities and Interdependence (Billett 1999)

Figure 1 - A sociocultural and sociohistorical basis for understanding work practice

Also depicted in Figure 1 are categories of 'activities' and 'interdependencies' to be used as units of analysis for describing the requirements for practice. These categories are a product of a literature review that focuses on delineating the requirements for performance in contemporary and emergent work practice (Billett 1999). The conceptionalisation of activities and interdependence are consistent with the sociocultural approach as they focus on the goal-directed activities that are the product of social practice and interactions with others and artifacts that are a basis of knowing and acting (see Cole 1998 or Wertsch 1991, 1998). Activities are held to be the manifestation of tasks (goal-directed activities) in the work practice, which are a product of its activity system, as they might be perceived typically by those engaged in it and experienced as common phenomena (Billett 1999). In particular, they are an embodiment of the requirements of situational factors that determine how sociocultural practice (e.g. occupational knowledge) is manifested in the particular context in the form of activities. However, it is important that they not be seen as "bundles of skills that are in some way separate from that social practice in which they are engaged" (Berryman 1993: 346). Consequently, these activities can only be understood fully when referenced to the conduct of actual practice and how these activities are manifested in that particular practice and are linked to interdependence located in that practice.

Requirements associated with Interdependence comprises interactions with others and artifacts (tools, technology, physical environment) that influence how individuals participate in, perform and construct understandings of and themselves are transformed by work practice (Billett 1999). It is these interactions that also mediate the application and development of the individuals' use of tools and artifacts that are engaged in that practice (see Resnick, Pontecorvo \& Saljo 1997 or Suchman 1997). Hence, interdependence is a key basis for understanding performance at work. Earlier, interdependence has been used to refer to "the extent to which unit personnel are dependent upon one another to perform their individual jobs" (Van de Ven, Delbecq, Keonig 1976:323). However, here the term is used more broadly and emphasizes the interdependency of agent, activity, world, meaning, knowing and learning (Lave 1991, Wertsch 1991, 1998). Similarly, the literature on the distributed character of knowing proposes that knowing is 'stretched' across the individuals and artifacts in social practice (Lave 1991), or as is referred to by others, as being distributed across situations (Resnick, Pontecorvo \& Saljo 1997). This means that it is necessary to account for the way knowing, and hence performance, is distributed across and interdependent with others and artifacts within the particular social practice. Recent critiques (e.g. Cobb 1999) have suggested that not all 
knowing is distributed across social systems such as workplace contexts. However, there is broadening acceptance that thinking and acting is not simply the product of the individual human effort but is dependent on the agency of artifacts and others in different ways (e.g. Wertsch 1998). This view of interdependency holds that interactions and tools do not simply facilitate an existing mental function while leaving it qualitatively unchanged, rather they are part of that change, with doing becoming learning (Wertsch 1991). Thus interdependence along with activities offer a means for understanding not only performance at work but also learning and how individuals are able to access practice, participate and develop their ability to perform in the role.

\section{Occupational view of vocational educators}

Like work of other kinds, vocational educators' practice is subject to periods of change and discontinuity in the work being done and how that work is done. The recent source of discontinuity is largely found in transformations of governmental economic and social goals. Governments in many countries have placed considerable demands upon vocational education systems to be responsive to policy goals associated with global competitiveness (OECD 1994). In doing so they have repositioning the social goals usually associated with publicly funded education systems. These demands are of two kinds; firstly, being responsive to new economic agendas as a public sector institution (e.g. becoming more responsive/competitive) and, secondly, as an educational system facilitating reforms in work and work practice (e.g. developing the skills required for the new economy). The resulting reorientation has led to changes to practice within vocational educational systems. Changes in the work tasks have included the kinds and scope of courses and content that are to be taught, the repositioning teachers' work to be more responsive to national economic goals and, specifically, those associated with performance in a global economy. Also, the displacement of parts of vocational educators' work (formulation of intent and content), the growth of tasks associated with being a consultant and marketer, and a greater concern with accountability and assessment have been demanded by enterprises, industry and government (Billett \& Hayes 1998). In terms of how vocational educators' work is being practiced, changes might include the use of technologies to work remotely with students, instruction within workplaces, and work increasingly being undertaken by teachers in part-time and/or contractual positions. Vocational educators' work has been repositioned, which has come to mean for many teachers, a marginalisation of their professional role and the casualisation of employment (Seddon 1997). In a number of countries, governments have also placed a central policy emphasis on vocational education being directly responsive to the demands of industry and enterprises in ways that sets vocational education apart from other educational sectors. In the United Kingdom, Australia and New Zealand and Germany, industry-led arrangements or agencies are used to determine the content of courses, standards for assessment and even, in some cases, the means by which courses are to be taught. Many and different kinds of consequences for vocational teachers' work flow from these arrangements. For example, commencing in the late 1980s and up until recent times, Australian governments cast vocational educators in the role of implementers of curriculum designed and determined by industry agencies (Billett 1995). Accountability came to be associated with meeting industry needs, with these requirements privileged over students' needs and aspirations. For example, in some situations the focus on assessment has overwhelmed the concerns for instruction in a quest to meet industry prescriptions. More recently, in countries such as the United Kingdom and Australia, there has been a shift for the highly specific needs of enterprises to be met in vocational curriculum (Department of Employment 1994, STB 1995, ANTA 1998). This shift brings with it the prospect of highly specific vocational training and a further re-positioning of vocational educators' roles and the goals for the programs in which they teach.

In some ways, the enterprise focus provides an expanded role for vocational educators in determining and responding to enterprise need (Billett \& Hayes 1998). However, in other ways, this focus is limiting and raises concerns of whose best interests are being served. The privileging of both industry and enterprise emphasis may well degrade and transform relationships between educators and their students. In doing so, it may well contest some key goals for professional practice by making students' interests subordinate to and only understood in terms of outcomes desired by enterprises and industry. Concerns about students' learning within these arrangements become conceptualized as closing the distance between what they currently know and the needs of the enterprise and how instruction can best deliver the outcomes required by the enterprise. Students' personal and vocational aspirations may be jeopardized by such an orientation to vocational education (or training), thereby complicating and compromising vocational teachers acting in the interest of their students. So in developing a view about what comprises vocational educators' work, contested and changing conceptions of the occupational role need to be acknowledged. 
Drawing on sociohistorical contributions, the sociocultural line of development provides a basis for delineating an occupational account of a vocational educator. This basis is founded on three interrelated considerations. These are: (i) through identifying the distinctiveness of the cultural needs for vocational educators; (ii) how these needs have transformed over time and, (iii) through understanding the contested character of a conception of occupational practice within a particular cultural setting.

\subsection{Distinctiveness of the need for vocational educators}

The culturally determined needs for vocational educators, as already foreshadowed, are distinct from those of educators in other educational sectors and sets them apart in a number of ways. These distinctions likely include: (i) a specific vocational focus or emphasis in much of the teaching effort; (ii) teaching cohorts of adolescent and adult learners, not all of whom have enjoyed success in compulsory education; (iii) the need to balance between the demands of powerful external sources of intents and content and those of students, (iv) the kinds of vocational courses taught and (v) broad range of activities expected of these educators. The goals for most vocational education courses, like many in higher education, are required to be of a kind specifically targeted towards work, perhaps more so than those in compulsory education. Therefore, judgements of worth are likely to be related directly to the applicability to work settings of what students have learnt in these courses. Also, perhaps more than higher or compulsory education sectors in western style democracies, the detail of course content and desired outcomes within vocational education are dictated by sources external to the sector. There are expectations that vocational educators should be highly responsive to these externally derived needs (OECD 1994). Also, the requirement to respond to the broad range of abilities and readiness of the adult student cohort in the vocational education sector makes parts of the teaching practice within vocational education quite distinct. Added to this, the requirement in some countries (but not all) for vocational educators to have many years of experience in their vocation problematises their identity. They may view their identity in terms of a combination of vocational and educational practitioner.

So there are a set of culturally determined needs that sets the needs for teaching in this education sector apart from others. However, it is not possible to be prescriptive about the occupational requirements of vocational educators across cultural settings, as their needs are not arrayed uniformly. For example, in the United States, views about vocational education, and hence the role to be played by vocational educators, are quite different from those in northern Europe. In the former, vocation education is often viewed as something for students who have not performed well in schooling, and its focus is seen largely in terms of transition from school to the workplace for these students. In northern European countries, conversely almost, vocational education is seen as providing valued vocational knowledge to students engaged in an educational sector established for that purpose and thereby assisting them realize their vocations, some of which have quite high status (OECD 1994). So in the northern European countries, vocational education has a different status and fulfils a more central and significant cultural need than in the United States. Yet, even across those countries that value highly vocational education the expectations of educators are constructed in different ways. For instance in Germany, there exists strong and mutually respectful relationships between industry and vocational educators that are a product of shared institutional arrangements (Carnoy 1998) that are largely absent in Australia, for instance. Also, the development of distinct educational systems, such as the community college system in the United States and the earlier division of vocational programs between Further Education colleges and Polytechnics in the United Kingdom, leads to vocational education provisions which are neither the same nor parallel in their development. One result of these different pathways of historical development and resulting need is differences in vocational educators' role and identity. For instance, different institutional arrangements over time in Australia and New Zealand have lead to quite distinct conceptions of vocational education in the two countries, despite their relative proximity in space. Moreover, in the United Kingdom, some of what would be undertaken in adult education courses in other countries is a central component of the provision of Further Education colleges along with more specific vocational education programs.

So cultural needs have determined roles for vocational educators that make them distinct from those in other sectors. Associated with this need come expectations and views about the roles of vocational educators. However, these cultural needs are not uniform. They need to be understood within the context of cultural settings such as nation or state or region within a country. Further, these cultural needs are not fixed in time, they are constantly transforming.

\subsection{Transformations over time}


The goals and procedures of vocational educators are constantly evolving and are transformed over time as much as space. Strongly associated with what has just been proposed above, the culturally determined needs for vocational education are transformed over time. In the mid- to late 1970s, for instance, the goals for vocational education set by government were to provide a general kind of education with a vocational orientation to prepare people for the world of work (OECD 1980, Kangan 1974). One aim of this view of vocational education was to develop students' ability to respond to the changing nature of work and assist them realize their personal and vocational education aspirations (Stevenson 1985). Consequently, vocational education was conceived as being a sector of education with an emphasis on the vocation in some countries. The more 'general' educational goals of this era can be contrasted with the more specifically and tightly vocational focus of recent times. Since the late 1980s the goals for the vocational education in countries such as Australia have come to focus on the skills required by industry (Dawkins 1988). Now in the late 1990s the focus appears to be shifting to meet the needs of particular or local enterprises (Department of Employment 1994, ANTA 1998). There are other likely culturally determined needs that contribute to conceptualising the occupation that will be subject to transformations over time. Particularly in times of high unemployment, employers might see the role in providing work-ready graduates whose courses have been tailored to the needs of particular enterprises (Billett \& Hayes 1999), whereas in times of high employment, employers had less ambitious and focussed demands (e.g. White 1985). Parents and students themselves want vocational educators to provide access to employable skills, yet those that are not so restricted as to inhibit mobility and career pathways (Billett \& Hayes 1999). In the United States also, interest in vocational education is influenced by levels of employment and, particularly, the success of school to work transition. The current low level of unemployment there is seen as a key reason for a reduced focus on and even the avoidance of reference to vocational education or it being seen as an anathema ${ }^{, 1}$. Further, the creation of a market-based provision of vocational education in countries such as England, Scotland and Australia has seen vocational educators' activities transformed. Some curriculum development tasks have been transferred to industry representatives, while other roles have expanded. It is now common for vocational educators to become consultants and advocates for their services in the market place (Billett \& Hayes 1999).

The contributions of sociohistorical considerations such as these are to assist understanding the evolution of the goals and other requirements for vocational education practice across time and space. In doing so, they provide a basis to understand the core values that endure or are themselves transformed. For instance, the focus on responding to students needs may endure. But its manifestation might be transformed to account for how these needs are to be met within particular enterprise requirements. So, as noted above, industry, government and enterprises are seen as strongly influencing curriculum and teaching practice in ways that are distinct from other sectors. Experienced teachers in compulsory education and those in higher education are unlikely to be asked to conform to the kind of external prescriptions demanded within vocational education. Because of this external influence, particularly those of government, discontinuity over time has come to characterize practice in this sector (Seddon 1997). Set among this discontinuity is contestation, not only between government and those who are asked to teach prescriptions, but also other interests in the cultural setting.

\subsection{Contested nature of sociocultural practice}

Cultural conceptions are unlikely to be singular or uniform. More than being conceived differently across cultures and time, the sociocultural conception of vocational educators' role is likely to be contested by different interests within the cultural setting. In short, the conception of roles and goals of the occupation of vocational education will be contested terrain. For example, governments might have one set of views about the competencies that it requires of vocational educators, as employees. Yet governments do not monopolize the occupational conception. Teacher unions, for instance, might have different views based around statements of ethics, professional autonomy or industrial practices, that might conflict with an industry or enterprise perspective of the requirements of vocational educators. Teachers themselves are likely to have a range of views about what comprises their work and whose interests should be privileged (e.g. students, industry or enterprise) and in what ways. Like the union view, teachers' views may not always be consistent with their employers' prescriptions. For instance, a current view is to see the outcomes of vocational programs as responding to the 'demand-side' rather than being premised on the supply-side. However, what comprises the demand-side is problematic. Governments might view enterprises and industry as best reflecting this interest. However, others might propose that individuals and regions, as consumers and contributors to VET also constitute the demand-side. So beyond industry, enterprise and

\footnotetext{
1 Discussion with US researchers in the post-compulsory education field David Stern, Cathleen Stasz, Mark Jury, Norton Grubb.
} 
individual needs are the requirement for vocation courses to also meet the needs of the communities in which individuals and enterprises are located. These communities have both common and distinct needs, as well as similar and different bases for vocational programs to proceed. From this perspective, the goals that drive vocational education and decision-making within it might be viewed "as developing individuals in order for them to realize their vocational and personal goals, contribute to the community as well as the productivity of their work practice, in a way that is robust and critical, not merely reductive”. However, such a reconciliation of interests may be difficult to achieve. Whereas enterprises often hold the view that vocational educators' should be focussed on meeting their specific needs, individuals in vocational education programs propose an key role for educators is to mediate against enterprise specific outcomes (Billett \& Hayes 1999). The same study found that industry views with concern enterprise specific arrangements that may inhibit transfer across the industry of which particular enterprises are a part

The different perspectives of these interest groups are also manifest when statements for credentialling or performance are advanced. The requirements for teacher registration may well embody or reflect government prescriptions about teacher performance. The particular sources and contributions selected by government or other agencies to write teacher competencies and courses that prepare teachers may well reflect those interests and concerns. However, given that views about the occupation are contested, simple aggregations and selectivity aimed to offer prescriptions about the qualities, dispositions and capabilities of vocational educators are likely to be of limited influence. This is likely to be particularly important in the context of teachers implementing what is contained within such prescriptions.

Table 1 - Occupational level: Activities and Interdependence

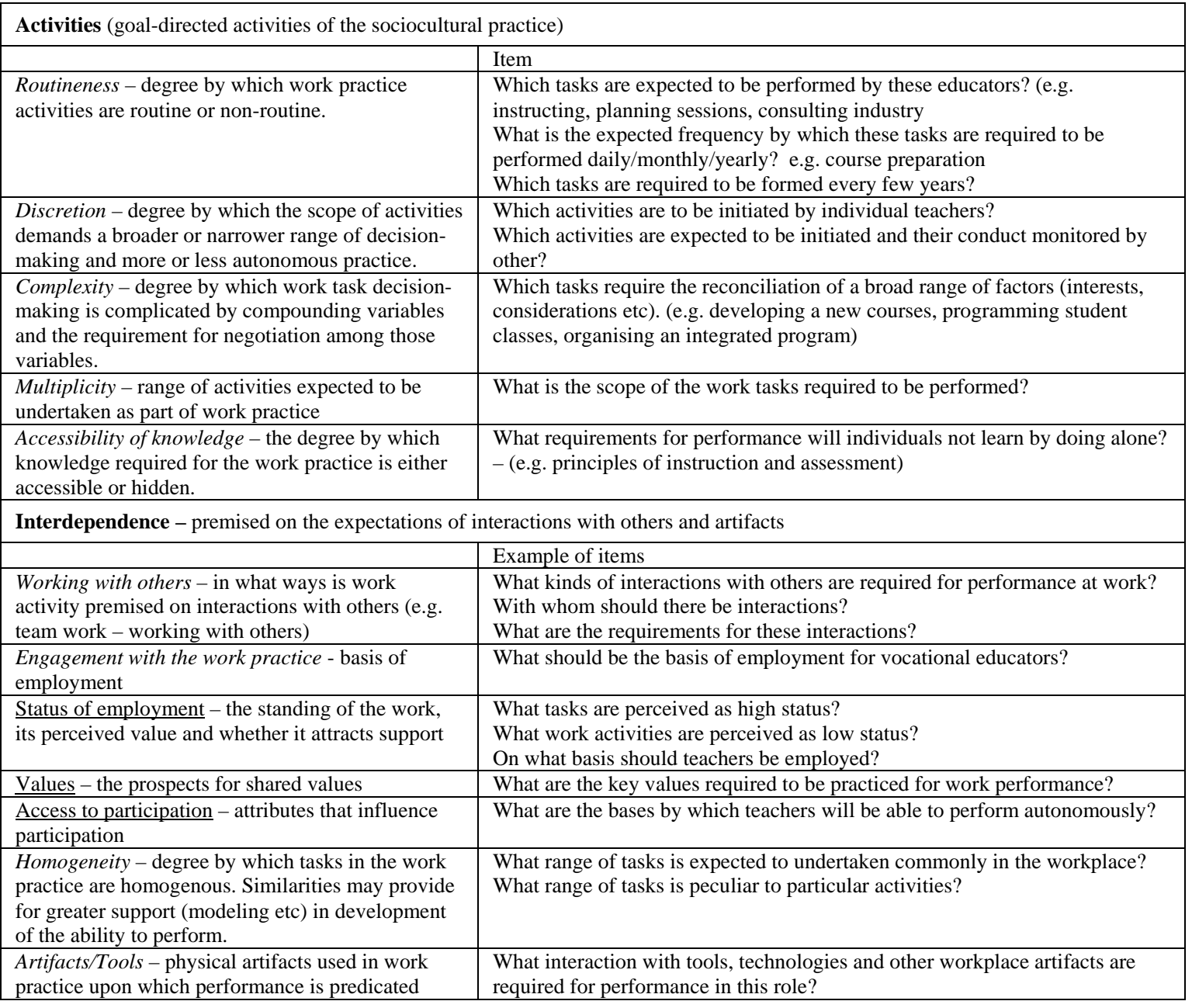

The degree of reciprocity of values between teachers' and others' conception of practice, in particular, is likely to have a significant impact on what actually happens in practice. Even if government or others where to prescribe a particular view there can be no guarantee that teachers will either be interested in or be able to implement it with fidelity because of individual interpretations, values or situational factors. There is a difference between what is 'intended' by those who control the formation of the intentions and content as 
stated in curriculum documentation and what is actually implemented. So, in so far as sociocultural practice reflects a cultural need for vocational educators, this need is likely to be contested and problematic both in its construction and implementation. Governments may desire a particular approach to occupational practice to be enacted and are not above using mechanisms to assert their conception. However, the implementation of educational practice in particular settings requires accounting for factors other than those prescribed by others who are remote from the circumstances in which teaching is enacted. Therefore, in seeking to identify the cultural determined conceptions of vocational educators it is necessary to account for perspectives that might contribute to that conception. It is likely much will be shared, but there will be areas of contestation and deliberation arising from difference of needs from within the culture.

As foreshadowed earlier and depicted in Figure 1, statement about activities and interdependence required for practice in the particular culture setting can be used as a means to define the particular sets of needs and reconcile where possible and highlight inconsistencies in needs. These dimensions were originally identified in a fuller form to identify and describe the requirements for practice in particular circumstances. However, here they can be used to capture the culturally derived requirements of vocational educators. In particular, at the occupational level, they can be used to generate broad statements of intent (e.g. goals) about vocational educators' performance - the goals to which these activities are to be directed - and list statements of activities that these educators could be expected to perform. These are depicted in Table 1.

The categories of activities and interactions, in Table 1 can be used to identify what connotes competent performance in vocational educators' practice in the particular setting, albeit through the multiple voices within that setting. These can be used to construct, reconcile and deliberate upon the goals for performance and likely activities required for this occupational practice. At this level, they can best be used to inform the requirements for performance in an ideal but disembedded way. Being disembedded from practice, their contributions should encompass the goals, values and activities that are to be particularly valued at that time within the culture. In this way, they can also be employed to propose, in non-specific way, the requirements for competent performance. As depicted in Figure 1, this analysis provides prescriptions in the forms of norms, practice and expectations. However, the term 'ideal' is used to suggest that the full requirements for practice can only be understood when the situational requirements of practice refine and augment those advanced at the occupational or sociocultural level.

\section{Situational factors}

The circumstances in which vocational educators' practice actually occurs are the product of situational factors, which can be understood as the activity system (Leontiev 1981) of the circumstances in which the practice is enacted. The activity system determines the division of labour, interactions, rules, norms of what constitute practice (Engestrom 1993). The actual requirements for performance will differ across situations; such as vocational colleges. For instance, teachers working in a large metropolitan college may be undertaking activities that are quite distinct from those in small non-metropolitan colleges. In metropolitan colleges, teachers might be members of a team, teaching the same content and able to specialize in a particular aspect of that content. Yet their counterparts in the non-metropolitan college may be the sole teacher of the vocation. They may have to teach across the range of content areas and at a range of levels. In addition, this teacher may have administrative roles that are undertaken by a sectional manager in the large metropolitan college. Additionally, the types of courses, their level and the degree by which those courses are integrated with the community outside the college, will vary from situation to situation as will the cohorts of students and their readiness to participate in particular courses. The educators' activities are also likely to differ in the way that vocational educators' practice includes activities both inside of as well as outside of the college. The latter might include consultancy, marketing, negotiating with enterprises and the community as well as activities within the college such as the development of resource materials and curriculum development that are likely to vary depending upon location. Each of these components of vocational educators' work has performance requirements that are quite distinct. That distinctiveness is manifested in the kinds of tasks that have to be undertaken. Not only are these activities likely to differ from situation to situation, but such is the array of situational factors that influence activities that it is difficult for them to be anything other than unique (Billett 1995, 1998, Trogan \& Grusenmeyer 1997). Therefore, the analysis of performance needs to include the particular situation where the practice is enacted. This is necessary to identify the requirements for practice at work, as it is only at the situational level of social practice that the requirements for performance can be identified.

4.1 Situational requirements: Activities and Interdependencies 
In this section, a scheme is advanced to identify and describe the requirements of performance in particular work practice. The requirements for performance varied across workplaces. Darrah (1997) proposes that. “jobs appear to be so diverse as to obviate the need generalizations about how people perform” (p.249). Yet while avoiding generalizations, it is necessary to have some common means of examining work practice and identifying the requirements for work performance. Consequently, this section proposes a scheme to understand the requirements of work practice comprising categories of activities and interdependencies. Under each of these categories, different kinds of activities and interdependencies have been synthesized from the literatures on work (Billett 1999). Rather than using an activity system approach that identifies the factors that determine practice, the approach adopted here is to identify and describe the requirements for performance flowing from the activity system. In doing so, three distinct kinds of contributions to understanding vocational educators' work can be made. These are: (i) statements about what is required for performance is in the workplace; (ii) the processes of learning through engagement in that practice; and (iii) how individuals access to that work practice are likely to be facilitated or inhibited.

\subsubsection{Goals for learning}

The items contained within each category identify what is required for performance in the particular vocational education settings. These then necessarily become statements for performance, and goals for learning in conjunction with the occupational knowledge identified at the sociocultural level. So, for instance, the degree by which work tasks in their entirety or in part are 'routine or non-routine', provide a basis for considering what procedures and understanding are required to perform competently (Table 2). Equally, statements in this table about the conception of 'working with others' will determine whether the tasks require the individual to participate as part of a team or as a subordinate and/or directly or indirectly negotiating with individuals outside the organisation (e.g. clients). Hence, the first contribution of these dimensions of work practice identified under Activities and Interdependence is for the characteristics of the work activities to be identified and described. This provides a basis for understanding the requirements for performance and formulating goals for developing that knowledge.

\subsubsection{Processes of learning}

The second contribution is that the categories of activities and interdependencies also inform about how these requirements are likely to mediate learning. Learning or knowing is held to be a product of engagement in activities (goal-directed activities). Individuals' engagement in practice is not separable from their learning or knowing, because doing and knowing are inseparable (Lave 1988). Much of this learning might comprise either the reinforcement of their knowledge or what they 'know', as well as securing new knowledge through engagement in activity. Therefore, the kinds of activities individuals participate in during their work practice provide a basis for understanding what they are likely to learn. Also, as knowledge is socially sourced, and some say distributed across social practice, the kinds of interaction individuals engage in with others and artifacts influence how and what they learn. So as individuals engage in activities in their work practice they learn from these experiences, for example from the routine or nonroutine activities that comprises their daily experience, and through negotiating the organisation of work (e.g. in teams). Yet, it is important to also emphasize the interdependence inherent in this work. To take another example, individuals working in circumstances remote from others (e.g. sole teacher) may find themselves engaged in patterns problem solving, premised on different kinds of interdependencies. Therefore, in multitudinous and complexes of ways, these interdependent dimensions of work practice mediate learning. Accordingly, more than just informing about goals for learning, these dimensions of activities and interdependencies also inform about the likely learning processes and outcomes inherent as individuals participate in the work practice. From these, understandings about initial preparation of teachers and their professional development might be assisted or inhibited by workplace experiences.

\subsubsection{Accessing work practice.}

Work is contested terrain. These dimensions of practice can be used to understand the contested nature of access to and participation in work practice. Conflictual relations between and among individuals, teams and key interest groups cannot be reduced to a mere footnote. They pervade work and performance within it. Whether it is between 'newcomers' or 'old-timers' (Lave \& Wenger 1991), full or part-time workers (Hughes \& Bernhardt 1999); teams with different roles and standing in the workplace (Darrah 1996, Hull 1997); between individuals’ personal and vocational goals (Darrah 1997) or among institutionalized arrangements such as those representing workers, supervisors or management (Danford 1998), contestation is an enduring feature of work practice. A key consequence of this contestation is its influence on access to work activities, and guidance and support in the workplace to learn the kinds of knowledge required for performance at work. Given understandings about the social basis of knowing and acting, it would be 
wholly derelict to only view matters of engagement in routine or non-routine activities or engagement in teams of different kinds as cognitive tasks without trying to understand the inherently contested nature of work practice. For example, the basis for granting access to non-routine activities may well distribute opportunities to become competent through practice. It is possible to identify direct educational consequences of this contestation (e.g. non-English speakers exclusion from work, reluctance of old timers to share knowledge). Moreover, this focus also informs about other aspects of work performance that influence access and engagement (e.g. power relations in working with others - teachers with administrators; contract teachers interacting with permanent teachers, administrators undermining teams when they threaten line management). Given the social organisation of work, an account of the ways in which this organisation is likely to assist or impede individuals' development is a necessary consideration for understanding vocational educators' performance. This may also inform about how their development is likely to be realised and what educational responses are required to reconcile contestation in the work of vocational educators.

In Table 2 below, the dimensions of activities and interdependence are presented. Activities within work practice are held to be described in terms of their: (i) Routineness; (ii) Discretion; (iii) Intensity; (iv) Multiplicity; (v) Complexity, and (vi) Accessibility. Interdependence within work practice are held to be describable as (i) Working with others (teams, clients); (ii) Engagement (Employment basis, Status of employment, Access to participation, Reciprocity of values), (iii) Homogeneity; and (iv) Artifacts/external tools.

Table 2 - Activities and Interdependence

\begin{tabular}{|c|c|}
\hline \multicolumn{2}{|c|}{ Activities (goal-directed activities - situational outcome of sociocultural practice) } \\
\hline & Item \\
\hline $\begin{array}{l}\text { Routineness - degree by which work practice } \\
\text { activities are routine or non-routine thereby } \\
\text { requiring robust knowledge. }\end{array}$ & $\begin{array}{l}\text { Which tasks are required to be performed daily/weekly? } \\
\text { Which tasks are required to be performed monthly/yearly? } \\
\text { Which tasks are required to be formed every few years? }\end{array}$ \\
\hline $\begin{array}{l}\text { Discretion - degree by which the scope of activities } \\
\text { demands a broader or narrower range of decision- } \\
\text { making and more or less autonomous practice. }\end{array}$ & $\begin{array}{l}\text { Which activities are initiated and undertaken based on individuals' initiative? } \\
\text { Which activities are initiated and conduct monitored by other? }\end{array}$ \\
\hline $\begin{array}{l}\text { Intensity - degree by which the intensity of work } \\
\text { tasks demands strategies for managing the } \\
\text { workload and undertaking multiple tasks } \\
\text { simultaneously. }\end{array}$ & What situations demand the conduct of multiple tasks simultaneously? \\
\hline $\begin{array}{l}\text { Complexity - degree by which work task decision- } \\
\text { making is complicated by compounding variables } \\
\text { and the requirement for negotiation among those } \\
\text { variables. }\end{array}$ & $\begin{array}{l}\text { Which tasks demand the reconciliation of a broad range of factors (interests, } \\
\text { considerations etc). (e.g. developing a new courses, programming student } \\
\text { classes, organising an integrated program) }\end{array}$ \\
\hline $\begin{array}{l}\text { Multiplicity - range of activities expected to be } \\
\text { undertaken as part of work practice }\end{array}$ & What is the scope of the work tasks required to be performed? \\
\hline $\begin{array}{l}\text { Accessibility of knowledge - the degree by which } \\
\text { knowledge required for the work practice is either } \\
\text { accessible or hidden. }\end{array}$ & $\begin{array}{l}\text { What requirements for performance will individuals not learn by doing alone? } \\
\text { - (e.g. principles of instruction and assessment) } \\
\text { What aspects of this work are difficult to learn? }\end{array}$ \\
\hline \multicolumn{2}{|c|}{$\begin{array}{l}\text { Interdependence - premised on the task distributed across other workers and artifacts - the mediational means determined by } \\
\text { situational factors }\end{array}$} \\
\hline & Instances / References \\
\hline $\begin{array}{l}\text { Working with others - in what ways is work } \\
\text { activity premised on interactions with others (e.g. } \\
\text { team work - working with others) }\end{array}$ & $\begin{array}{l}\text { What kinds of interactions with others are required for performance at work? } \\
\text { What are the requirements for these interactions? }\end{array}$ \\
\hline $\begin{array}{l}\text { Engagement with the work practice - basis of } \\
\text { employment }\end{array}$ & $\begin{array}{l}\text { What are the consequences for performance for being a part-time, and/or } \\
\text { contract worker, and/or a worker remote from others? }\end{array}$ \\
\hline $\begin{array}{l}\text { Status of employment }- \text { the standing of the work, } \\
\text { its perceived value and whether it attracts support }\end{array}$ & $\begin{array}{l}\text { What work activities are perceived as high status? } \\
\text { What work activities are perceived as low status? }\end{array}$ \\
\hline $\begin{array}{l}\text { Reciprocity of values }- \text { the prospects for shared } \\
\text { values }\end{array}$ & $\begin{array}{l}\text { What are the key values required to be practiced for work performance? } \\
\text { Which of these are likely to be in conflict with personal and professional } \\
\text { values? } \\
\text { Which of these are likely to concur with personal and professional values? }\end{array}$ \\
\hline $\begin{array}{l}\text { Access to participation - attributes that influence } \\
\text { participation }\end{array}$ & $\begin{array}{l}\text { In what ways will participation in work practice be eased? (e.g. same } \\
\text { disciplinary base, collegiate relations, language skills) } \\
\text { In what ways will participation in the work practice be inhibited? }\end{array}$ \\
\hline $\begin{array}{l}\text { Homogeneity - degree by which tasks in the work } \\
\text { practice are homogenous. Similarities may provide } \\
\text { for greater support (modelling etc) in development } \\
\text { of the ability to perform. }\end{array}$ & $\begin{array}{l}\text { What range of workplace tasks is undertaken commonly in the workplace? } \\
\text { What range of tasks is peculiar to particular individual's activities? }\end{array}$ \\
\hline $\begin{array}{l}\text { Artifacts/Tools - physical artifacts used in work } \\
\text { practice upon which performance is predicated }\end{array}$ & $\begin{array}{l}\text { What interaction with tools, technologies and other workplace artifacts are } \\
\text { required for workplace performance? }\end{array}$ \\
\hline
\end{tabular}


The sections of Table 2 provide a fuller description of factors associated with activities and interdependencies. In the left-hand column of both sections are definitions of each of the situational factors. In the right-hand column are questions that seek the elicit responses and some illustrative examples for the focus of responses are also included. These then provide a basis for gathering responses at the situational level about the requirements for practice. These items, or similar, can be used to identify and describe the requirements for performance in situations where vocational educators' practice is enacted. It is these requirements that form the basis for goals for performance. They can also be used to describe the means by which individuals will learn through participation as well as factors likely to assist or inhibit access to and participation in that work practice. These requirements can be analyzed in conjunction with the occupational viewpoint(s). From this, and where appropriate, reconciliation between the two sets of needs can proceed. It is anticipated that this process of reconciliation will be used to both detail and refine the views about practice developed at the occupational level while enriching that at the situational level.

\section{Mediation between occupational needs and situational requirements}

From what has been proposed above, two sets of conceptions of teachers' practice need to be considered in understanding vocational educators' competence. The 'idealized', but contested, occupational view proposes 'what should be', yet it is disembedded from actual practice. It cannot be observed and takes the form of prescriptions that respond to a set of cultural needs comprising government, industry, enterprises, parents etc etc. In contrast, the situational analysis provides a description of actual practice that is embedded in a particular situation. It can be observed and is responsive to situational factors that are unlikely to be comprehensible at the level of cultural need that is used to conceive the occupation. The demands of two levels or lines of socially based development have therefore been identified. Each makes an important and distinct contribution to our understanding of what comprises competence in vocational educators' practice. For instance, an analysis of practice might reveal requirements that are counter to the sociocultural conception of practice. The occupational contribution of the ideal provides a filter by which judgements can be made about the quality of situational imperatives (what is). An analysis of a particular vocational education practice might identify activities or interdependencies that are, for instance, counter to students' long-term interests. The students may be being taught enterprise-specific content or the educators' discretion is being eroded to a degree that challenges the kinds of ideals set out at the sociocultural level. Alternatively, the demands of actual practice can be used to inform occupational expectations, such as the role and scope of the tasks. Together, they provide an account of competence that should be mutually beneficial. Consequently, the description of the requirements for practice is more than embedding the analysis in practice. It also provides a means to consider situational requirements against sociocultural needs in order to evolve both the idealized sociocultural conception and the imperatives of situational requirements.

The reciprocity and tensions between these two lines of social development not only identifies but permits judgements about the evolving nature of vocational educators' practice. The contributions of the two levels may be set in tensions which can be reduced by the application of views about what should comprise the goals for vocational education (i.e. those relating to individuals, communities as well as employers) that was advanced earlier. However, as the concept of competence cannot be wholly situational or occupational it requires mediation between these two views. The ways different interest groups render such mediation is indicative of the problematic idea of prescribing teachers' competence at work.

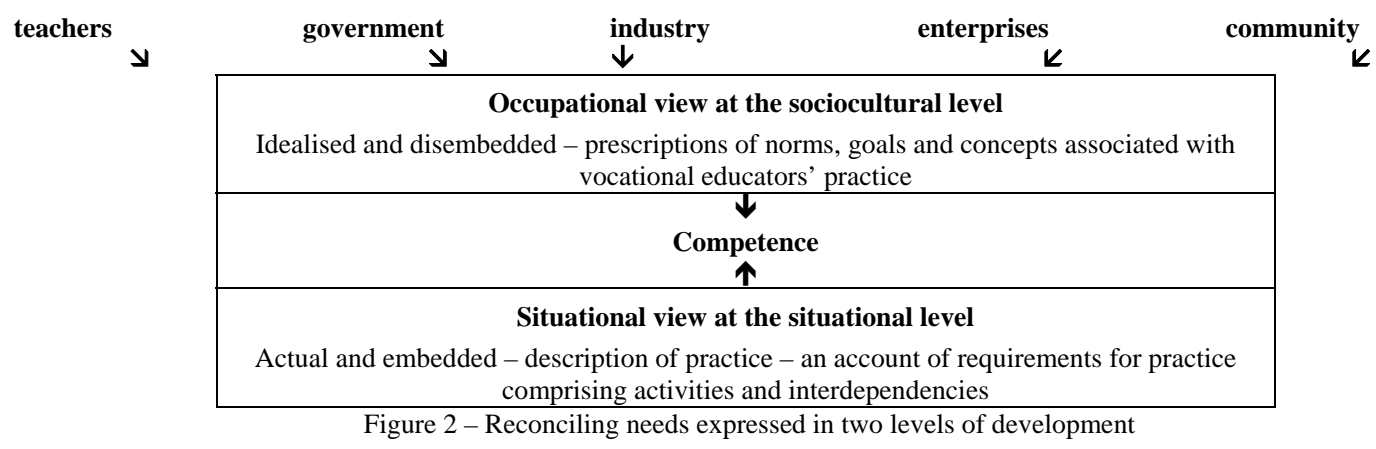




\section{Summary}

The ideas presented aim to contribute to the larger project of understanding the relationship between the social world and the mind. This project goes beyond merely claiming that there is a social basis to knowing. It also focuses on the institutional factors that influence how and what individuals learn through social practice. The larger goal is to understand the sources of knowledge and constructions of meaning within cultures and communities. Consequently, and in sum, this chapter has proposed a way to think about, identify and describe what comprises competence for vocational educators. The approach avoids being prescriptive. It is not possible to be prescriptive, because situational and occupational levels of analysis need to be delineated, identified and reconciled. Such reconciliation will be constructed differently according the concerns and goals of those involved. In this way it responds to socially determined needs as expressed through two lines or levels of development. Yet, rather than being merely reactive to situations it uses reciprocity and tensions between the occupational (sociocultural level) and the situational (community of practice) levels to construct a view of competence which can be critically constructed. The chapter has employed what Cole (1998) refers to as cultural-historical activity theory to the task of identifying competence in the work of vocational educators. The key advance here is the fashioning from this theory a basis for understanding the requirements of practice that is founded in the manifestations of practice itself. So whereas the activity system approach is useful for informing about the factors that determine practice, the scheme presented earlier aims to understand the requirements for practice itself. Moreover, the detailing of the factors of activities and interdependencies at both the occupational and workplace levels offers an analysis of the social practice that is situated in sociohistorical and sociocultural lines of development, and embedded in the enactment of practice. The purpose of cultural-historical activity theory is to understand further the relationship between the social world and the mind. Hopefully, the analysis presented here has contributed something to this understanding.

Acknowledgements. The author wishes to acknowledge the support of the Fulbright Commission, the Australian, National Training Authority, the School of Vocational, Technology and Arts Education at Griffith University that made the writing of this chapter possible.

\section{References}

Australian National Training Authority (ANTA) (1998), National Strategy for Vocational Education and Training 1998-2003 Draft for Consultation, Brisbane 20 March 1998

Berryman, S. (1993). Learning for the workplace. Review of Research in Education, 19, 343-401.

Billett, S (1999) Changing work, practices and engagement: Understanding performance at work. Faculty of Education, Griffith University

Billett, S. R. (1998). Situation, Social systems and learning. Journal of Education and Work (Nov 1997) - Volume 11 No 3 pp. 255274.

Billett, S \& Hayes S (1998) Meeting the demand: The needs of VET clients. National Centre for Vocational Education Research. Adelaide

Billett, S. (1995). Structuring knowledge through authentic activities. Unpublished doctoral thesis. Griffith University, Brisbane, Australia.

Billett, S, McCann, A \& Scott, K (1998) Workplace mentoring: Organising and managing effective practice. Centre for Learning and Work Research, Griffith University. ISBN 0868579149

Carnoy M (1999) The great work dilemma: Education, employment and wages in the new global economy. In (eds. J. Ahier \& G Esland) Education, Training and the Future of Work 1. Routledge London Australian National Training Authority (ANTA) 1998, National Strategy for Vocational Education and Training 1998-2003 Draft for Consultation, Brisbane 20 March 1998

Cobb P (1998) Learning from distributed theories of intelligence. Mind, Culture, and Activity 5 (3) 187-204.

Cole M (1998) Can cultural psychology help us think about diversity? Mind, Culture and Activity, 5 (4) 291-304.

Cole, M. (1985). The zone of proximal development where culture and cognition create each other. In J. V. Wertsch (Ed). Culture, communication and cognition: Vygotskian perspectives. (pp. 146-161). Cambridge: Cambridge University Press.

Danford, A (1998) Teamworking and labour regulation in the autocomponents industry. Work, Employment \& Society vol 12, no 3 pp.409-431.

Darrah C (1997) Complicating the concept of skill requirements: Scenes from a workplace In (G. Hull (ed) Changing work, Changing workers: Critical perspectives on language, literacy and skills. (pp. 249-272). New York, State University of New York Press.

Darrah C N (1996) Learning and work: An exploration in Industrial Ethnography. Garland Publishing, New York:

Dawkins, J (1988), Industry Training in Australia: The Need for Change. Canberra, Australian Government Publishing Services.

Employment Department, (1994), Training in Britain: A guide. London: Employment Department

Engestrom, Y. (1993). Development studies of work as a testbench of activity theory: The case of primary care medical practice. in S. Chaiklin \& J. Lave (eds). Understanding Practice: perspectives on activity and context. (pp. 64-103). Cambridge, U.K.:Cambridge University Press.

Hughes K \& Bernhardt A (1999) Market segmentation and the restructuring of banking jobs. IEE Brief number 24 February 1999 , Institute on Education and the Economy, New York.

Hull G (1997). Preface and Introduction In (G. Hull (ed) Changing work, Changing workers: Critical perspectives on language, literacy and skills. State University of New York Press, New York.

Kangan M (1974) TAFE in Australia. Report on the needs of technical and further education. Canberra. Australian Government Printing Service.

Lave J (1991) Situated learning in communities of practice. In L B Resnick, J M Levine \& S D Teasley (eds.) Perspectives on socially shared cognition. (Pp.63 -82). APA. Washington DC. 
Lave, J., \& Wenger, E. (1991). Situated learning - legitimate peripheral participation. Cambridge University Press, Cambridge. Leonteiv, A.N. (1981). Problems of the development of the mind. Moscow: Progress Publishers.

Luria, A. R. (1976). Cognitive development: its cultural and social foundations. Cambridge: Harvard University Press.

Organisation for Economic and Co-operation and Development (1994), Apprenticeship: Which way forward? OECD, Paris.

Organisation for Economic Co-operation and Development. (1980). The competencies needed in working life. Report by a Group of Experts. OECD, Paris.

Resnick L B, Pontecorvo C \& Saljo R (1997) - Introduction - In LB Resnick, C Pontecorvo \& R. Saljo (eds.) Discourse, tools and reasoning: Essays on Situated Cognition. Springer, Berlin (pp1-20).

Rogoff, B. (1990). Apprenticeship in thinking - cognitive development in social context. New York: Oxford University Press.

Seddon T (1997) Education: Deprofessionalised? Or reregulated, reorganised and reauthorised. Australian Journal of Education.

Scribner, S. (1985). Vygostky's use of history. In J. V. Wertsch (ed). Culture, communication and cognition: Vygotskian perspectives (pp. 119-145). Cambridge University Press, Cambridge

Scribner, S. (1984). Studying working intelligence. In B. Rogoff \& J. Lave (eds.). Everyday cognition: Its development in social context (pp. 9-40). Cambridge, Mass: Harvard University Press.

Scribner, S., \& Beach, K. (1993). An activity theory approach to memory. Applied Cognitive Psychology, 7, 185-190.

State Training Board, Victoria (1995), Trends in Vocational Education and Training, Melbourne, Australia: State Training Board.

Stevenson J C (1985) Curriculum Development in TAFE: General education versus skill-based education,. Curriculum Perspectives 5 (1) $\mathrm{pp} 57-61$

Suchman, L (1997). Centers of coordination: A case and some themes. In LB Resnick, C Pontecorvo \& R. Saljo (eds.) Discourse, tools and reasoning: Essays on Situated Cognition. Springer, Berlin. (p.41-62).

Trogon A \& Grusenmeyer C (1997). To Resolve a technical problem through conversation. In LB Resnick, C Pontecorvo \& R. Saljo (eds.) Discourse, tools and reasoning: Essays on Situated Cognition. Springer, Berlin. (pp.87-110).

Van de Ven, A H, Delbecq A L \& Keonig R Jr (1976) Determinants of co-ordination modes within organisations. American Sociological Review 41 pp322-338.

Vygotsky, L. S. (1978). Mind in society - the development of higher psychological processes. Cambridge: Harvard University Press.

Wenger E (1998) Communities of practice: Learning, meaning, and identity. Cambridge Cambridge University Press.

Wertsch J.W. (1998) Mind as action. Oxford University Press. New York.

Wertsch J W (1991) A sociocultural approach to socially shared cognition. In L B Resnick, J M Levine \& S D Teasley (eds.) Perspectives on socially shared cognition (pp 85-100). American Psychological Association. Washington DC.

Wertsch, J. V. (ed) (1985). Culture, communication and cognition: Vygotskian perspectives. Cambridge: Cambridge University Press.

White M A (1985) TAFE’s Curriculum Dilemma: Leader or Follower’ Curriculum Perspectives 5 (1) pp.61-64. 